\title{
Book Review of Blended Learning in Action: A Practical Guide Toward Sustainable Change
}

\author{
Heidi Rowland \\ Boise State University
}

Citation: Tucker, C. R., Wycoff, T., \& Green, J. T. (2016). Blended learning in action: A practical guide toward sustainable change. Thousand Oaks, California: Corwin.

200 pages, \$18.12 at Amazon, ISBN: 978-1-5063-4116-3

\section{Book Review of Blended Learning in Action: A Practical Guide Toward Sustainable Change}

Tucker, Wycoff, and Green's Blended Learning in Action: A Practical Guide Toward Sustainable Change provides useful information for K-12 educators looking to differentiate instruction in a blended learning environment. Tucker is an experienced Google-certified teacher, best-selling author, trainer, consultant, and speaker. Wycoff is a specialist in technology integration and blended learning who works as a school leader and learning platform designer. Green is an adjunct professor, speaker, nonprofit board member, and consultant. All are experienced in blended learning integration in the K-12 environment, and the information they present in this book is in keeping with literature stressing the importance of differentiation in increasing student achievement, particularly when paired with Understanding by Design (UbD).

While this book is most appropriate for those in a K-12 learning environment, it would most likely be useful for those designing lessons for postsecondary instruction as well, particularly as students who are accustomed to blended personalized learning move into higher education settings. This book does help with informing those who make the overall instructional and financial decisions, but the most helpful portion of the book, the second half, is powerful for teachers looking to use blended learning to individualize instruction to better meet the interests, preferred methods of instruction or assessment, skill levels, or other modifications or accommodations for specific student social and educational needs. The information here is not only helpful to teachers new to personalization, but because it provides various ways to address students, create smaller learning communities within the class, and adjust the content and delivery of information, it could also help teachers who want to expand their repertoire of techniques for differentiation. Since planning is paramount in using these models effectively, this gives teachers the opportunity to slowly introduce and practice new ways of using them in the classroom. Also, each chapter has book discussion questions, and several sections include useful templates for planning and graphics for timelines of making the shift from the traditional classroom to digital differentiated learning and information, such as the roles of stakeholders, the visioning processes, and elements of 
effectiveness in blended learning. The vocabulary and style make the information conveyed very accessible. These elements make this book ideal for a summer- or semester-long book study for a leadership team, school committee, group of educational technology consultants, or any other group that would utilize this information to make a shift to individualized blended learning.

The first half of this book is important for administrators and technology coordinators who ultimately make the decisions about when and how to make a shift to a blended learning culture, as well as what hardware and platforms to purchase. However, the real power of this book for teachers and professional development providers lies within Chapters 6 through 13. While the authors sprinkle in useful information in the form of applications for teachers and leaders, teacher vignettes, and real-world examples, it is when they begin to explain the benefits and drawbacks to three major differentiation techniques which blended learning allows for that the true benefits of this work become apparent.

The authors begin with a breakdown of timelines necessary for fostering a blended learning culture within a school system, encouraging risk-taking and empowerment of both students and educators as active learners. This begins with collaboratively building a vision, assessing the realities of the current system, designing this transition and what it will look like, and prepiloting a test run of intended changes. Individualization isn't limited to students here but also involves looking closely at the needs of the educators who will be a part of this process and meeting their technological and pedagogical needs. Based upon these needs, the school will then decide on productivity suites, learning management systems, devices, applications, and other resources involved.

An important shift in the book takes place when the authors describe the power of digital curricula to reduce the time needed to personalize and differentiate instruction and give timely feedback to students. Teachers must prepare students with the technical and self-learning advocacy skills they need in a blended learning classroom so that they can learn to understand and address their own learning needs. This self-sufficiency allows the teacher to move into facilitator or coaching role and help the students to be even more self-directed. Tucker, Wycoff, and Green remind readers that "through personalization, students become primary stakeholders in their learning" (p. 67). Obviously, this places significant emphasis on planning, for which they suggest using the UbD framework with ongoing formative assessments to gauge student progress and adapt the learning to each student's needs. This opens their discussion in the following chapters of three major types of differentiation that blended learning supports - the station rotation model, the whole group rotation model, and the flipped classroom - and gives examples, benefits, and drawbacks to each.

Station rotation allows a teacher to develop smaller communities of learning within the class, engage students in the learning in different ways, and have more personalized direct interaction with students to target different skills. However, the teacher must consider and plan for assessments to determine student understanding of the objectives, roles of the students and teacher, and student understanding of the skills, as well as how to save time in giving direction to the 
students and ensuring that students have other activities ready when they finish so as not to become distractions to the other students.

Whole group rotation, on the other hand, uses online elements to differentiate pace and do away with the need for students to move to different stations around the room. It also allows the teacher to have individualized time with students while others are working. The drawback here is a need for software or some technique to monitor student computer use to ensure students remain on task.

The flipped classroom model also allows for individualization and differentiated pace since students can access information outside of class and have the teacher for help as needed while they work on activities in class. The challenges this presents involve keeping students motivated and engaged with an activity by offering a connection or critical thinking activity with it and dealing with lack of student access to technology outside of the classroom.

The authors advocate using a blend tailored to the needs of the class, but they do not offer adequate advice on the best methods for specific types of learning goals. Teachers and administrators can sometimes focus on technology for the sake of innovation, losing sight of the fact that these techniques are meant to help meet student needs. The authors emphasize that the learning objectives, not the technique or technological aspect, should still be what drives the lesson. With that in mind, it would have been more helpful to see how the methods align with depth of knowledge levels. Overall, however, this book offers helpful information on personalized learning in the blended classroom. 